ISSN: 0213-2087 eISSN: 2444-7080

DOI: http://dx.doi.org/10.14201/shhc201836151160

\title{
SER UNA Y NO OTRO
}

\section{Be one and not another}

\author{
Dominique GAY-SYLVESTRE \\ Universidad de Limoges, Francia \\ dominique.gay-sylvestre@wanadoo.fr
}

Recepción: 27/04/2018 Revisión: 17/05/2018 Aceptación: 12/07/2018

RESUMEN: Los relatos de vida de Ismena y Carla, trans que viven en Sonora (México) son parte de una investigación de terreno llevada a cabo por la autora sobre las condiciones de vida y los derechos de esta población en el seno de la sociedad mexicana y más particularmente sonorense, hoy día. Su voluntad de ser lo que profundamente anhelan choca con la mentalidad patriarcal imperante y la homofobia. Los testimonios de las dos trans ponen de realce su situación dramática e, implícitamente, la de muchas otras.

Palabras clave: mujeres trans; Sonora; condiciones de vida; derechos humanos.

RÉSUMÉ: Ismena et Carla vivent dans l'état du Sonora (Mexique). Leurs récits font partie d'une recherche de terrain menée par l'auteur, sur les conditions de vie et droits de l'homme des transgenres, au sein de la société mexicaine et, tout spécialement, celle du Sonora (au nord du Mexique), en but à la mentalité patriarcale et à l'homophobie, malgé leur volonté d'être ce qu'ils désirent au plus profond d'euxmêmes. Les témoignages des deux trans dont il est question dans cet article montrent bien la situation dramatique à laquelle ils sont confrontés et, de façon implicite, celle de nombreux autres trans.

Mots clés: femmes trans; Sonora; conditions de vie; droits de l'homme. 
Han aceptado encontrarme y helas aquí en el cuarto del hotel donde me hospedo en la capital sonorense ${ }^{1}$, de pie, con pantalones vaqueros y sin maquillaje. No me dan sus nombres de pila sino los que quieren que yo recuerde: Carla e Ismena $^{2}$. Ambas son trans, ejercen el trabajo sexual y son activistas ${ }^{3}$ en la asociación Diverciudad ${ }^{4}$. Los primeros minutos son algo incómodos y no sabemos cómo entablar la conversación. Es difícil contarse y es también complejo para el otro, que en ese caso soy yo, asimilar lo que ve y, en ese momento, imagina.

El timbre del celular de Carla rompe el malestar... Ismena aprovecha la interrupción para sentarse en el borde de la cama y me enseña una foto en la que aparece en un desfile del que salió ganadora. Luce realmente espléndida. La felicito, lo que disminuye la tensión y facilita la relación con ella.

Mientras Carla se ha apartado para concertar una cita con el cliente que la llamó, Ismena empieza a recordar...

Siempre he tenido muchos problemas en relación con la identidad sexual, mucha cultura católica, mucha religión. Desde que uno nace, dicen: 'esto es bueno, esto es malo; te vas a ir al infierno, no debes decir así'... Yo, cuando era niño, creía que era niña hasta que entré a la primaria. Allí me quedó bien claro de que era diferente y me recuerdo que, a veces, me pegaban pero no sabía por qué. Por ejemplo mis papas... mi mamá me regañaba y me pegaba "no hagas esto". Yo no entendía por qué. No me explicaban, hasta que entré en la primaria. ¿Por qué me pegaban? Por conductas afeminadas que un niño varonil no debe de tener. Entonces yo a veces pensaba que mi hermana era igual que yo. Yo todavía hasta me acuerdo que una vez estábamos los dos orinando antes de dormirnos y le dije no sé cómo, ni sé qué me fije: «ay, te van a salir así como a mí; pensamos que era igual, para colgarse, como a mí los huevitos». Me pegaron mucho... porque ni debía jugar con las cosas de mis hermanas, ni nada de eso, hasta que entré a la primaria, que me empezaron a llamar jotito ${ }^{5}$, o sea joto o jotito es cómo decir, gay, güir, maricón o marica en España... Yo me acuerdo que, un día, dos amigos, al segundo día de clases, ya no se juntaron para jugar ni hablar conmigo, porque sus papás les habían dicho que no se juntaran conmigo porque se iban a hacer jotitos. Entonces cuando yo llegué y a mi mamá le pregunté ¿por qué? me pegó en la boca que no andará repitiendo eso... La adolescencia, la secundaria, igual o sea vivir y hacer el "bulling" como le dicen ahora. Y, pues, la preparatoria. Entré a clases de teatro, de arte dramático para ser un poco más varonil. Cuando entré en la universidad fue cuando me enamoré de un muchacho. Estaba conmigo también en clase, pero como yo no quería aceptar esos sentimientos, fui con el siquiatra. Me tocó una siquiatra homofóbica que me empezó a dar testosterona y no me acuerdo qué tantas pastillas que me iba a curar,

1. Hermosillo, Sonora, México.

2. Nombres dados por la autora para respetar el anonimato de las entrevistadas.

3. «Luchando más que nada por lo que se responden a los derechos de nosotras en cuanto a autoridades, a policías», comenta Ismena.

4. Asociación creada en 2007 para "promoción del valor y la práctica de la no discriminación en la sociedad y las personas que viven con VIH/Sida».

5. Término popular mexicano para calificar a un homosexual. 
que me iba a quitar el deseo. Afortunadamente es un hospital público de salud ${ }^{6}$. Para los siguientes meses, la cambiaron y mandaron a otra y me dijo que no, que la homosexualidad era perfectamente natural, que todo lo que me estaba dando la mujer lo único que iba a hacer era que yo iba a tener voz ronca y llenarme el cuerpo de pelo. Así me lo dijo la mujer... para que me aceptara y ya me empezó a ayudar, a platicarme de hombres de la historia, de personajes, ... y ya pues yo, vivir ${ }^{7}$.

No hay resentimiento en Ismena. Ha superado esta fase, pero el recuerdo ha hecho resurgir momentos dolorosos del pasado. El origen social, humilde, de sus padres explica, en parte, el rechazo, la voluntad de negar -incluso a golpes- lo que, en su inocencia, el cuerpo y la mente del hijo expresan. Hay mucho miedo también: miedo a lo desconocido, al qué dirán, en una sociedad fuertemente impregnada por un machismo y una hombría de otra época que aprisionan los comportamientos y confortan los tabúes y prejuicios.

Represión sin nombre que se vale de la idea «de que la naturaleza se equivoca» ${ }^{8}$ y que, en ese caso, hay que recurrir a un diagnóstico médico para acabar con un «desorden de identidad de género» (id.) para que se respeten y se cumplan con las "concepciones dominantes de género» $(i d$.), en conformidad con una sociedad patriarcal que «[...] construye sus dispositivos de poder/saber para conformarlos/as a sus conceptos y regímenes de identidad" $(i d .)^{9}$.

Represión que es parte de un proceso que

[...] poco a poco irá cubriendo todo el dispositivo de sexualidad, dándole el significado de una interdicción generalizada... Un vínculo histórico la enlaza con la difusión del dispositivo de sexualidad. Justificará, por un lado, su extensión autoritaria e imperiosa, enunciando el principio de que todo tipo de sexualidad ha de ser sometido a la ley; aún más, que solo es sexualidad por el efecto de la ley; no solo tiene que someter su sexualidad a la ley, sino que solo tendrá sexualidad ciñéndose a la ley ${ }^{10}$.

Pero ¿de qué ley hablamos? Una ley impositiva y coercitiva que no permite cambiar las reglas, que legitima la exclusión, la condena moral y el rechazo social, en lugar de dar cabida a unas representaciones y prácticas culturales y sociales que permitan una modificación de la mirada y de los hábitos mentales.

6. Se trata del hospital Carlos Navas en Hermosillo.

7. Ismena: entrevista con la autora. Hermosillo, febrero de 2014.

8. NúÑEz NoRIEGA, G.: ¿Qué es la diversidad sexual? Reflexiones desde la academia y el movimiento ciudadano. Quito (Ecuador): Ediciones Abya-Yala y CIAD, 2011.

9. Los sujetos trans hombres o trans mujeres.

10. «[... va peu à peu recouvrir tout le dispositif de sexualité et lui donner le sens d'un interdit généralisé... Elle est historiquement liée à la diffusion du dispositif de la sexualité. D’un côté elle va justifier son extension autoritaire et contraignante, en posant le principe que toute sexualité doit être soumise à la loi, mieux, qu'elle n'est sexualité que par l'effet de la loi: non seulement il faut soumettre votre sexualité à la loi, mais vous n'aurez de sexualité que de vous assujettir à la loi». (Foucault, M.: Histoire de la sexualité. T.1, «La volonté de savoir». Paris: Gallimard, 1994, pp. 169-170).

Traducción nuestra. 
Más aún cuando esta violencia opera en los ranchos de "los poblados rurales que hay en las afueras de Hermosillo", "pueblos chiquitos e infiernos grande" sonorenses donde encontramos, combinados, ignorancia, peso de la Iglesia y de las conveniencias, ya que en

[...] provincia, se exacerban el humor fácil y la hostilidad hacia los imposibilitados de fingimiento, y en todas partes, un desviado que auspicia la grandeza en términos compartidos de los que los ${ }^{11}$ ven o tratan. Si se les "nota" (voz, modales, ligues, soltería), la mirada social los vuelve fenómenos» ${ }^{12}$.

La solución para la que optará Ismena, será la huida para poder expresar su diferencia y que salga a relucir su yo verdadero para poder vivir de modo digno. Pero es un proceso largo que requiere afrentar nuevas pruebas, taparse con diferentes máscaras, para un día -es de suponer- poder quitárselas y enfrentar, sin miedo, la mirada del otro e intentar -ya tan solo intentar-vivir plenamente. Así es que, cuenta Ismena:

Por la secundaria me vine por acá para la ciudad ${ }^{13}$ y fue como me quedé aquí estudiando y viviendo con mis tíos; pero, ellos también, muy homofóbicos y machistas. Mi libertad fue cuando terminé la universidad y me fui a EE. UU. porque allá me empecé a vestir de mujer y fue cuando me realicé y tuve mis primeros encuentros sexuales.

Pero, iqué confusión en la expresión de esta libertad! Lejos de la ideología dominante y en un como exilio en Estados Unidos, Ismena se convence de que el libertinaje sexual y nuevos modos de portarse le traen cambios significativos. El desenfreno que caracteriza este periodo es una reacción visceral a la violencia psíquica, mental y hasta física que ha tenido que aguantar.

Sin embargo, se construye:[...] destacando una diferencia que le confiere un sentido a una experiencia existencial, hasta entonces vivida como algo confuso o sin esperanza; o, también, encuentra en ella los recursos simbólicos que le permiten derribar un estigma que la negaba como sujeto, o le prohibía expresarse como tal ${ }^{14}$.En ese momento, Ismena se siente feliz; pero solo es una sensación engañosa, consecuencia de la distancia que ha puesto con su entorno familiar y social. Cuando encuentra al que va a ser su novio durante seis años, cree que la felicidad está

11. En esta cita, el autor se refiere a los homosexuales. Sin embargo, su comentario también es válido para los transgéneros.

12. NúÑEZ Noriega, G.: Masculinidade intimidad: identidad, sexualidady sida. Distrito Federal, México: Miguel Ángel Porrúa, 2007, p. 25.

13. A Hermosillo.

14. "[...] en mettant en avant une différence qui confère un sens à une expérience existentielle, jusque-là vécue comme confuse ou sans espoir; ou bien encore, elle y trouve les ressources symboliques lui permettant de renverser un stigmate qui la niait comme sujet, ou lui interdisait de s'exprimer en tant que tel». (Wievionka, M.: La différence. Paris: Balland, Voix et Regards, 2001, p. 142.

Traducción nuestra. 
a su alcance. En realidad, lo que va a vivir es tan violento, aunque diferente, como lo que ha intentado sobrellevar hasta su ida "del otro lado". En efecto, el novio vive mal la relación con Ismena; su sexualidad y hasta su imagen se ven perturbadas frente al otro yo. Son, entonces, seis años de psicoterapia para ambos durante los cuales él insiste en que Ismena regrese a México para proceder a un cambio de sexo total. Pero, cuenta Ismena:

[...] fui a México a los encuentros de activistas y de trans y allí averigüé con las chicas que ya se habían hecho cambio de sexo, si convenía o no convenía... 8 de cada 10 chicas me dijeron que no me operara: 'iaie! no, ni te vayas a operar porque ya no puedes volver a sentir; ¡tu vida sexual ya no es la misma!' El ejemplo más fácil que me propusieron es hacer una cortada: 'Te haces una cortada, tienes una cicatriz y con el tiempo sigues sintiendo sensación, pero al cabo de unos años ya no sientes nada'15.

Sin embargo, el tratamiento a base de estrógenos le ha facilitado el crecimiento del pecho y le ha disminuido la barba. Ismena tiene ahora el pelo largo, aunque atado. Al igual que muchas otras trans que buscan, a todo trance, cambiar su apariencia física para sentirse más a gusto consigo mismas, sin llegar a una transformación total, además del crecimiento del pecho, va a recurrir a los servicios de una amiga trans que le inyecta (para ella es gratuito) aceite para tener unas nalgas "duras y atractivas». Pero no «del aceite de carro, que este sí es peligroso y ha provocado la muerte de otras compañeras" precisa Ismena. "Detalle» que no deja de alertar y pone de realce el estado psíquico en el que se encuentran algunas trans y la misma Ismena para estar acorde con lo que consideran en extremo como el canon de belleza femenino. El riesgo mortal, incluso, no es un impedimento para algunas de ellas, tan apremiante es el deseo de que uno y otro cuerpo no formen sino un todo completo y que puedan realizar sus sueños. En los avisos necrológicos en los periódicos, la muerte de una trans pasa desapercibida, solo llorada por otras trans y algunos cuantos familiares. Por si fuera poco, es muy complicado encontrar al (a la) que le inyectó el aceite letal: la víctima es una trans; por tanto, se considera lo hecho ¡como un mal menor!A pesar de sus transformaciones físicas, la relación de Ismena con su novio fracasa. Los traumas psicológicos son muy profundos y la vivencia con Ismena demasiado compleja. Además se requieren tiempo, comprensión y paciencia para que funcione la terapia. Por otra parte, el regreso a Sonora es marcado de nuevo por estigmas y discriminaciones, que un tiempo, se habían desvanecido en los Estados Unidos y que Ismena creía haber dejado atrás.

Al nivel laboral, primero. En efecto, si la Constitución Política del Estado Libre y Soberano de Sonora dicta que: "Los Derechos del Hombre son la base y el objeto de las instituciones sociales» y que "En el Estado de Sonora todo individuo gozará de las garantías que otorga la Constitución Política de los Estados Unidos Mexicanos» (29 de marzo de 1917: 1), en la práctica:

15. Ismena: entrevista con la autora. Hermosillo, febrero de 2014. 
muchas de las leyes son letra muerta: las autoridades, las personas que trabajan, los funcionarios o sea los municipales, policía en algunos casos, anteponen sus prejuicios morales, religiosos, a lo que la ley dice ${ }^{16}$.Eso trae como consecuencia, en el caso particular de los/las trans, el buscar alternativas que permitan ingresos, sin que, por ello, se tenga que enseñar documentos oficiales de identidad. El sexoservicio es, en muchos casos, la opción, si no la más fácil, en todo caso la más rentable, ya que, en el campo del sexo, las trans tienen mucho éxito entre la población masculina. Este dato, recurrente, aludido en varias oportunidades por las trans que entrevistamos, pone de realce una faceta poco conocida de la sociedad y no propiamente sonorense. De hecho, cuenta Ismena, "Hay muchos bisexuales que les gusta tener a la mujer; no sé si es para casarse con ella o para tapar la apariencia y a la sociedad.... ${ }^{17}$.

Pero, si hay trans a quienes les gusta ejercer el trabajo del sexo, ninguna de ellas puede ocultar que la prostitución, ya de por sí peligrosa, para lo/as que la ejercen, es aún más arriesgada para este grupo social. No solo porque representan una competencia que las trabajadoras del sexo consideran como desleal, sino que ocurre que los mismos clientes castiguen a la trans con quien tuvieron una relación sexual: ¿sentimiento de culpa, de vergüenza que hay que intentar curar a través de un acto violento? Lo cierto es que muchas de las trans que se prostituyen en Hermosillo, tuvieron que sufrir, un día, violencia y vejaciones. A Ismena, por ejemplo, la llevó un cliente en su carro y la abandonó, de noche, desnuda, sin peluca, sin tacones, a la salida de la ciudad.

Nada más recordar el suceso cuando se le anublan los ojos. Al tiempo que intenta, torpemente, secarse las lágrimas, busca una explicación: "[...] ellos tienen terror muchas veces y, a lo mejor, por el terror que tienen nos agreden» ${ }^{18}$. «Terror» al acto sexual ejercido con una trans y al significado que encierra; odio inconsciente hacia sí mismo y, sí, consciente hacia la otra, la culpable, la provocadora y al mismo tiempo una homofobia que lucha con lo que revela el acto sexual con una trans, de su ser más profundo e íntimo.

En todo caso, esta mala experiencia y el miedo que experimentó, llevaron a Ismena, así como a muchas otras trans, a utilizar internet, menos peligroso, aunque no siempre menos arriesgado:

Le digo: "deposítame, mándame saldo o crédito por el teléfono celular y yo dejo que me veas y me toco frente a la cámara si tú quieres". O "me pones esta tarjeta en mi celular o me depositas en Banco Aztecal o Copel, los bancos que hay aquí, muy populares. Mándame la ficha escaneada y luego despositas". Cuando deposita, el viernes en la noche o el sábado en la noche, el hombre está allí en su casa, se masturba, yo aquí le modelo lencería. Le gusta mucho ver las partes masculinas con

16. Id.

17. Id.

18. Ismena: entrevista con la autora. Hermosillo, febrero de 2014. 
ropa femenina o uno pintado y hago así y modelo y porque sí me da un poquito miedo ir a la calle, por esa experiencia ${ }^{19}$.

Así que, por su condición, Ismena se ha acostumbrado a solo tener parejas ocasionales, amantes clandestinos. Su vida no es sino un largo camino solitario, de poca o nula autoestima y de mucha vagancia, entrecortado por empleos episódicos y sesiones públicas de karaoke, en las que, de noche, muy maquillada, abandona su vestimenta masculina y se desliza en unos vestidos sedosos y coloridos. Sale a relucir cantando, sola o con otras trans en los bares que organizan espectáculos públicos. Feliz, por fin realizada, ya no «uno» sino «otra». Alejada, un tiempo, por muy breve que sea, de lo sórdido de una vida diaria en la que prevalecen desilusiones de toda clase.

Pero, cuando ya las luces, todas, se apagan, solo le queda el maquillaje que no ha podido quitarse aún y los pantalones vaqueros que se ha puesto de nuevo para sumirse, una vez más, en un cotidiano que la atropella y no le da salida alguna. La inestabilidad financiera y psicológica en la que se ve hundida muy a menudo y que no la deja en paz, y como único refugio, una vivienda prestada, destartalada, a menudo blanco de ladrones que roban sus pelucas, zapatos de tacones y vestidos de mujer, no le permiten encarar debidamente el presente y mucho menos el futuro.

Estudió en la universidad; incluso, obtuvo un Master en comunicación. Pero es trans y se reivindica como tal, así que le es imposible acceder a un empleo regular: de nada le sirve que se prevalga de su diploma y mucho menos cuando en este se lee, inscrito, el nombre de una persona, ajena a lo que es Ismena. De vez en cuando, la contratan unos amigos homosexuales, conocedores de su situación, dueños de una tienda de zapatos: el tiempo para ella para rehacerse financieramente y vivir de manera algo más decente.

La vida no le ha regalado nada; casi siempre fue objeto de rechazo: por parte de sus padres, de sus colegas, de sus novios. Incapaz de guardar una pareja e imposibilitada en ocupar un empleo que le correspondería, ha pensado muchas veces en el suicidio, pero «ni eso lo logró» recuerda.

Remembranzas todas que traen a la mente vacíos que no se han podido colmar, heridas aún sin cicatrizar y una interrogante sin nombre acerca de un futuro de contornos borrosos en el que Ismena no reconoce si es o no es, está o no está: una y no otro u otro, pero ya no totalmente otra.Carla que ha terminado su plática telefónica ha estado escuchando con atención nuestra charla. Aprovecha una breve pausa en los recuerdos de Ismena para informarnos que un cliente, de paso por la capital sonorense, acaba de llegar y la espera en la habitación de su hotel: «... cuando un cliente viene aquí o te habla por teléfono para una cita, te dicen "en el hotel te espero" y ya vas al hotel y ya cobras más. Es bien cobrado» ${ }^{20}$.

19. Id.

20. Clara: entrevista con la autora. Hermosillo, febrero de 2014. 
En principio, está prohibido el trabajo sexual en dichos lugares, pero suele pasar y el recepcionista, con una buena propina, se hace el de la vista gorda. Tampoco es el único. Sin entrar en detalles, explica Carla que algunos policías so pretexto de «vigilar a la gente que nos asedia, nos empiezan a extorsionar» e intimidan a los clientes, amenazando de "que nos van a sacar en el periódico por andar en la prostitución".

Pero, ocurre también que unos clientes, avergonzados por un acto sexual que no logran asumir..., o porque simplemente quieren sacar provecho de una situación fuera de la norma, discutan el precio o se rehúsen a pagar por el servicio dado:

Ha habido casos, hace tiempo en que no me pagaban; ahora no, yo cobro por adelantado. Si no hay dinero por adelantado, no importa lo que digan. Normalmente, el cliente te dice '¿No crees en mí?' ¡Aie, mijo ${ }^{21}$ !, no puedo creer en una tabla pues ¿cómo voy a creer en ti, si no te conozco? ${ }^{22}$.

Sin embargo, corta Ismena:

...en Hermosillo, están las principales universidades; muchas veces se viene del interior del estado o de otros estados... para la gente que se viene de fuera, que no tiene ningún familiar aquí, es más fácil decir soy gay, soy lesbiana, soy trans,... porque no está su familia que los cuida. Para la gente que es de aquí, que vive aquí, que crece aquí, que tiene miedo al estigma, a la discriminación,... entonces todos estos factores yo creo que se conjuntan para hacer que la gente pague por el silencio de no decir de lo que a mí me gusta en la intimidad... y estar contigo ${ }^{23}$.

Y que «no cometieron ningún pecado» añade Clara pues «así somos; así no hay ser igual; no somos iguales" ${ }^{24}$, de tal forma que, a fin de cuentas, complementa Ismena "... la gente paga por el secreto, por sentirse libre, porque te calles, es este silencio" ${ }^{25}$.

A diferencia de Ismena, a Clara nunca le ha pasado por la mente hacerse una reasignación integral: “¿Cambiar sexo? ¡No! ¡Me muero de hambre!» exclama. Además, explica: «así cobras más». En otros términos, si bien es cierto que su voluntad desde muy pequeño es ser mujer, no cabe duda de que ella sabe cómo usar su nueva apariencia física para hacerla más rentable y lucrativa:

¡Claro que saben que soy trans! Aprenden a identificar... Yo he estado con hombres que creen que soy mujer y ya estando en el cuarto, ya muchos sacan... Aie, pues yo no sabía que tú eras hombre. Es que no se puede... Yo siempre les digo. No puede llamar engaño si nunca me preguntaste. Ahorita, tienes que preguntar.

21. "Mi hijo".

22. CF supra nota 18.

23. Ismena: entrevista con la autora. Hermosillo, febrero de 2014.

24. Clara: entrevista con la autora. Hermosilo, febrero de 2014.

25. Ismena: entrevista con la autora. Hermosillo, febrero de 2014. 
¿Cómo nos identifican?Por la forma de vestirte. Por ejemplo, nosotras, en cuestión de trabajo, nos arreglamos más, nos vemos más vistosas, más llamativas; hacemos más para arreglarnos, para vernos mejor ${ }^{26}$.

Sigue entre Ismena y Clara un corto intercambio mediante el cual ponen de realce la afirmación y reivindicación de su diferencia, de una identidad particular y bien labrada:Muchos dicen [que somos] más femeninas que las mismas mujeres, porque a veces creo yo que en el trabajo sexual el que quiere sacar algo, pues invierte mucho. Una muchacha trans... el maquillaje, la combinación de la ropa, más elegante, más fashion, más... ${ }^{27}$....que le quitó la celulitis, qué bonita la zapatilla, el cuerpo firme, que el busto... 28 .

El perfume, el peinado... ${ }^{29}$.

Actitudes y modales que no pueden pasar desapercibidos y, que, de hecho, son concebidos para llamar la atención y alcanzar un reconocimiento que tanto les hace falta, una manera de reivindicar que son lo que ellas quieren ser y que la gente vea lo que ellas quieren que vea. En realidad, no es así de sencillo. Si en la calle llevan un atuendo y maquillaje que les permite presentarse como mujeres y ser consideradas como tales, la mirada que dan al mundo es muy insegura.Clara, incluso, cree necesario aclarar que «Empiez[a] a trabajar a la hora que [le] empiece a sonar el teléfono» ${ }^{30}$ recalcando y reivindicando en esa forma, una libertad de acción que, se supone, autoriza su misma condición. Atenderá únicamente y si se le antoja, las llamadas de sus clientes potenciales. Pero, en la práctica es algo diferente. Por supuesto, no correrá riesgos aceptando citas azarosas -aunque nunca puede estar segura de estar fuera de peligro-, pero ella depende del trabajo del sexo para vivir y no puede ejercer otro en una sociedad que reparte a los seres entre buenos y malos. Ella es parte de los malos. Claro que no es una santa ni mucho menos, pero, haciendo caso omiso de su existencia, la sociedad también favorece, en parte, este tipo de comportamiento.

El estatuto de transgénero aunado al de trabajadora del sexo refuerza la vulnerabilidad y precariedad de este grupo social, privándole de una existencia legal. Estos ciudadanos que votan, pagan impuestos y tasas como cualquier otro ciudadano viven una dualidad que el derecho y los políticos no toman suficientemente en cuenta. Por cierto, no todo/as lo/as transgénero/as se dedican al trabajo sexual pero la exclusión a la que están sometido/as y que ha de solucionarse, les inclina a ejercer este servicio.

No se trata aquí de buscar culpables a unas situaciones cuya complejidad ha hecho que no se las ha atendido en su debida forma. Se trata simplemente de dar cuenta de condiciones de sufrimiento, desesperación y desilusión a las que se

\footnotetext{
26. CF supra note 22.

27. CF supra note 23.

28. CF supra note 22.

29. CF supra note 23.

30. También trabaja por internet.
} 
enfrentan seres humanos que necesitan que se encuentren salidas, a la vez humanas y jurídicas a partir, tan solo para empezar, del cumplimiento de los derechos de género dictados en los Principios de Yogyakarta sobre la Aplicación del Derecho Internacional Humanitario en Relación con la Orientación Sexual y la Identidad de Género ${ }^{31}$.

Tal vez así Ismena, Clara y muchas otras trans podrán ser lo que siempre han querido ser, sin que necesiten reivindicar, justificar y explicar: «Soy una y no otro".

\section{REFERENCIAS}

Barrios Martínez, D., García Ramos, M. A.: Transexualidad: la paradoja del cambio. MéxiCO: Editorial Alfil, 2008.

Bruckner, P.: Le Paradoxe amoureux. Paris: Grasset, 2009.

Constitución Politica del Estado Libre y Soberano de Sonora.

Foucault, M.: Histoire de la sexualité. T.1, "La volonté de savoir», 1994.

HérITIER, F.: Masculin/Féminin II. Dissoudre la Hiérarchie. Paris. Odile Jacob poches, 2012.

NúÑEz Noriega, G.: ¿Qué es la diversidad sexual? Reflexiones desde la academia y el movimiento ciudadano. Quito (Ecuador): Ediciones Abya-Yala y CIAD, 2011.

NúÑez Noriega, G.: Masculinidad e intimidad: identidad, sexualidad y sida. Distrito Federal, México: Miguel Ángel Porrúa, 2007.

Toro-Alfonso, J. (ed.): Reflexiones en torno a la Sexualidad y el Género. Guatemala City: Universidad del Valle de Guatemala, 2007.

Velasco Morales, V.: Vestidas para educar. México: CECASH, 2011.Wieviorka, M. (2001). La différence. Paris: Balland, Voix et Regards, 2001.

\section{ENTREVISTAS CON LA AUTORA}

Ismena, Hermosillo, febrero de 2014.

Clara, Hermosillo, febrero de 2014.

31. Ver al respecto los Principios de Yogyakarta sobre la Aplicación del Derecho Internacional Humanitario en Relación con la Orientación Sexual y la Identidad de Género de 2006, presentados en marzo de 2007 ante el Consejo de Derechos Humanos de las Naciones Unidas en Ginebra. 